\title{
Calculation of Transformer Inrush Currents occurring during the Energizing of the Public Grid after a major Black Out
}

\author{
C.P.J. Jansen; J.G. Slootweg and R.A.C.T. de Groot
}

\begin{abstract}
The paper describes simulations and a live test of the black-start procedure of an industrial power plant in the North of the Netherlands. After a total blackout of the Public Grid in the Netherlands, the restoration process shall start with so-called black-start units. To increase the probability that the re-energizing of the Public Grid indeed succeeds, the Dutch transmission system operator obliges units to prove their blackstart capability by performing a live test.

A crucial step in the re-energizing of the Public Grid is the energizing of large transformers. Problems can be expected due to the inrush current of the transformers. For one such generating unit extended simulations of the inrush phenomena of the transformers and calculation of inrush currents and overvoltages were performed. Based on the simulation results well-founded decisions were made on the most suitable start-up procedure. The simulations were followed by live tests of the black-start procedure.
\end{abstract}

Index Terms-Inrush Current; Grid Black Out; Grid Restoration; Transformer Energizing.

\section{INTRODUCTION}

A FTER a total blackout of the Public Grid, and separation of all connected power plants, the restoration process begins by starting the generating units designated (or contracted) as black-start units. Black-start units are capable of starting without external power supply. A black-start is usually performed with the aid of a diesel unit or a gas turbine unit to supply the auxiliary systems of the main unit. Once running, the generating unit is connected to the Public Grid [1].

A crucial step in the re-energizing of the Public Grid is the energizing of the main unit's step-up transformer or the first grid (step-down) transformers. These grid transformers are of similar or even higher rating than the generating unit. Problems can be expected due to the inrush current of the transformers. These currents are large in amplitude, are

This work is done by KEMA T\&D Consulting and Essent Netwerk B.V. and was supported by Delesto B.V. and by TenneT bv, the Dutch Transmission System Operator.

C. P. J. Jansen and R. A. C. T. de Groot are with KEMA T\&D Consulting Arnhem, The Netherlands (e-mail: kees.jansen@kema.com).

J. G. Slootweg is with Essent Netwerk B.V. 's-Hertogenbosch, The Netherlands (e-mail: han.slootweg@essent.nl ). strongly non-sinusoidal and can last for several minutes. There is a risk that protection devices respond to these currents, causing the generating unit to trip. In addition, resonance overvoltages can occur caused by the transformer non-linear impedance and the line or cable capacitance together with the weak damping of the system [2], [3].

One way to energize the transformers is by performing a so-called soft start of the complete circuit generator-step-up transformer-grid transformer. For a soft start, first the connections between generator and transformers are made. Then the generator is started without excitation voltage. If the generator runs at no load and full speed, the excitation current of the generator is increased. The gradual increase of the applied voltage avoids inrush currents. Drawback is that the procedure deviates from the normal start-up procedure of the unit and also affects the protection scheme and possible interlocks.

To increase the success rate of the re-energizing of the Public Grid after a total black out, the Dutch transmission system operator (TenneT) obliges contracted generating units to prove their black-start capability by performing a live test.

For one such generating unit, an industrial power plant in the North of the Netherlands, extended simulations of the inrush phenomena of the transformers and calculation of inrush currents and overvoltages were performed. Based on the simulation results, well-founded decisions were made on the most suitable start-up procedure. The simulations were followed by live tests of the black-start procedure.

\section{ORIGIN OF INRUSH CURRENTS}

The working principle of a transformer is governed by Faraday's and Ampère's laws [4-6]. Faraday's law states that induced voltage is equal to the derivative of flux linkage, or, stated differently, that the coupled flux equals the integral of the applied voltage. Ampère's law relates the flux linked by a coil to the current flowing through it.

During normal operation, the transformer current and voltage, as well as the flux in the iron core, vary sinusoidally. When the transformer is not loaded, i.e. one of the terminals is open, the phase shift between voltage on the one hand and flux and current on the other, is approximately 90 degrees.

Assume now that the transformer is idle and a voltage is 
applied. When the presence of remanent magnetism is neglected and the connection happens at the instant at which the flux would equal zero during normal operation, i.e. at the voltage's maximum, this does not give rise to any exceptional current or flux. The flux is the integral of the applied voltage and is exactly equal to what it would be if this had not been the first period of the applied voltage.

However, when the transformer is connected at the moment that the voltage equals zero, the flux will reach twice its normal height when integrating the voltage. Had the transformer already been connected, the integration would have started from the negative maximum of the flux and end at the positive maximum of the flux. However, because this is the first period of the voltage, the integration starts at zero flux and the flux reaches twice the maximum value occurring during normal operation.

Because these high flux densities, the iron core is driven into saturation. Therefore, the transformer starts to exhibit non-linear behavior. As a result, the current is no longer approximately proportional to the flux. Instead, much more current is needed to increase the flux and the current can easily reach much more than two times its maximum. This large current is referred to as the inrush current. As stated earlier, inrush currents can lead to undesirable effects, such as the triggering of protection devices and resonant overvoltages. The presence of remanent magnetism can increase this effect, leading to even larger inrush currents.

\section{MODELING}

\section{A. System description}

The systems studied in this paper consist of transformers and generators in island operation, as depicted in figure 1. The generators have a rating of $34 \mathrm{MVA}$ and $50 \mathrm{MVA}$ at a voltage of $10.5 \mathrm{kV}$. The first generator is connected to a $66 \mathrm{kV}$ busbar through a 20.0 MVA $10.6 / 66 \mathrm{kV}$ transformer. It is driven by a gas turbine. The second generator is connected to the same $66 \mathrm{kV}$ busbar through a $50 \mathrm{MVA}$ transformer and is also a gas turbine unit.

To investigate the inrush phenomenon and to validate the developed models, firstly a second 20.0 MVA $10.6 / 66 \mathrm{kV}$ transformer is connected to the $66 \mathrm{kV}$ busbar (system $a$ in figure 1). In the next case also a $160 \mathrm{MVA} 66 / 220 \mathrm{kV}$ transformer is connected to this $66 \mathrm{kV}$ busbar (system $b$ in figure 1). In the first case, only one generator is in operation, whereas in the second case, both are in operation. The relevant parameters of the generators are given in table I and of the transformers in table II.

The parameters not given in the generator documentation have been estimated and are marked with *. The one-line diagrams of the systems are depicted in figure 1.

The generators and transformers were each modeled in two different software packages, namely ATP and DIgSILENT Power Factory.
TABLE I

GENERATOR PARAMETERS

\begin{tabular}{|c|c|c|c|c|c|}
\hline \multirow[t]{2}{*}{ Quantity } & \multicolumn{2}{|c|}{ Value } & \multirow[t]{2}{*}{ Quantity } & \multicolumn{2}{|c|}{ Value } \\
\hline & Gen 1 & Gen 2 & & Gen 1 & Gen 2 \\
\hline $\mathrm{S}_{\mathrm{nom}}$ & $34.08 \mathrm{MVA}$ & $50 \mathrm{MVA}$ & $\mathrm{X}_{\mathrm{q}}{ }^{\prime}$ & 0.5 p.u.* & 0.5 p.u.* \\
\hline $\mathrm{U}_{\text {nom }}$ & $10.5 \mathrm{kV}$ & $10.5 \mathrm{kV}$ & $\mathrm{X}_{\mathrm{q}}{ }^{\prime}{ }^{\prime}$ & 0.131 p.u.* & 0.151 p.u. \\
\hline $\mathrm{X}_{1}$ & 0.10 p.u.* & 0.10 p.u.* & $\mathrm{X}_{0}$ & 0.075 p.u. & 0.085 p.u. \\
\hline $\mathrm{R}_{\mathrm{I}}$ & 1.481 mp.u. & 1.317 mp.u. & $\mathrm{T}_{\mathrm{d} 0}{ }^{\prime}$ & $6,54 \mathrm{~s}$ & $5.49 \mathrm{~s}$ \\
\hline$X_{d}$ & 2.007 p.u. & 1.910 p.u. & $\mathrm{T}_{\mathrm{d} 0}$, & $0,04 \mathrm{~s}^{*}$ & $0.018 \mathrm{~s}$ \\
\hline$X_{d}{ }^{\prime}$ & 0.194 p.u. & 0.226 p.u. & $\mathrm{T}_{\mathrm{q} 0}{ }^{\prime}$ & $0,50 \mathrm{~s}^{*}$ & $0.04 \mathrm{~s}^{*}$ \\
\hline $\mathrm{X}_{\mathrm{d}}{ }^{\prime \prime}$ & 0.131 p.u. & 0.151 p.u. & $\mathrm{T}_{\mathrm{q} 0}$, & $0,15 \mathrm{~s} *$ & $0,15 \mathrm{~s}^{*}$ \\
\hline$X_{q}$ & 1.8 p.u.* & 1.72 p.u.* & & & \\
\hline
\end{tabular}

TABLE II

TRANSFORMER PARAMETERS

\begin{tabular}{|l|l|l|l|}
\hline \multirow{2}{*}{ Quantity } & \multicolumn{3}{|c|}{ Value } \\
\cline { 2 - 4 } & Transformer 1,2 & \multicolumn{1}{|c|}{ Transformer 3 } & Transformer 4 \\
\hline $\mathrm{S}_{\mathrm{nom}}$ & $20 \mathrm{MVA}$ & $50 \mathrm{MVA}$ & $160 \mathrm{MVA}$ \\
\hline $\mathrm{U}_{\mathrm{HV}}$ & $66 \mathrm{kV}$ & $70.5 \mathrm{kV}$ & $220 \mathrm{kV}$ \\
\hline $\mathrm{U}_{\mathrm{LV}}$ & $10.6 \mathrm{kV}$ & $10.5 \mathrm{kV}$ & $66 \mathrm{kV}$ \\
\hline $\mathrm{U}_{\mathrm{k}}$ & $14.7 \%$ & $11.0 \%$ & $17.8 \%$ \\
\hline $\mathrm{P}_{\mathrm{Cu}}$ & $87.6 \mathrm{~kW}$ & $116 \mathrm{~kW}$ & $459 \mathrm{~kW}$ \\
\hline $\mathrm{P}_{0,100 \%}$ & $10.3 \mathrm{~kW}$ & $31.3 \mathrm{~kW}$ & $71.4 \mathrm{~kW}$ \\
\hline $\mathrm{I}_{0,100 \%}$ & $0.77 \mathrm{mp} . \mathrm{u}$. & $2.3 \mathrm{mp} . \mathrm{u}$. & $1.04 \mathrm{mp} . \mathrm{u}$. \\
\hline
\end{tabular}
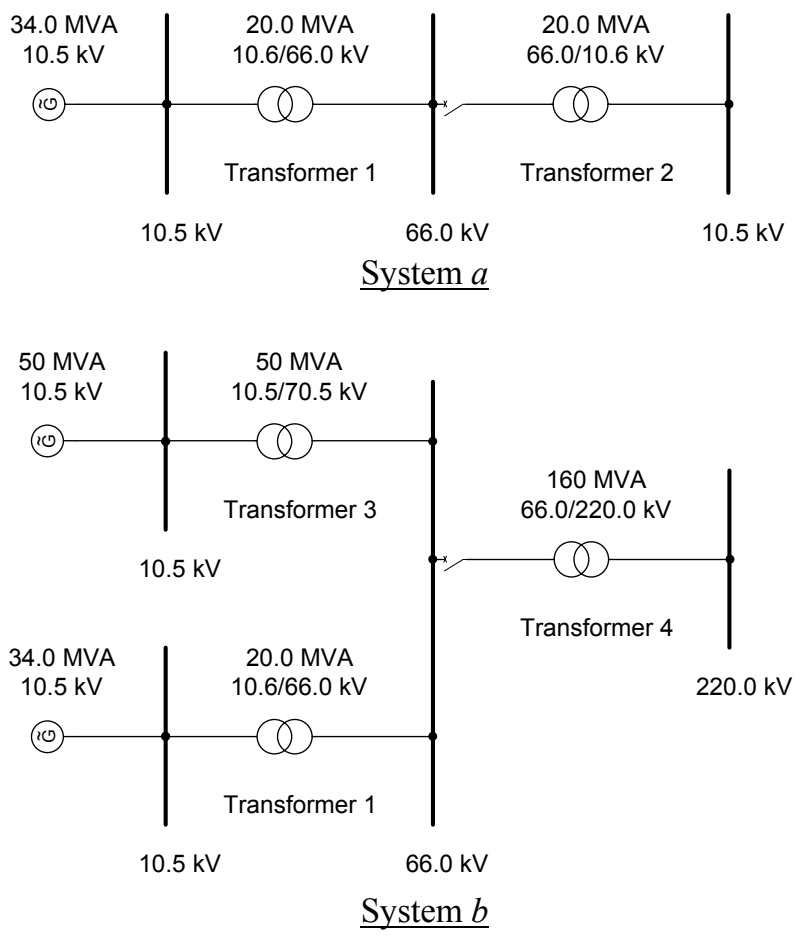

Fig. 1. Investigated systems $a$ and $b$

\section{B. ATP Model}

The ATP model was developed using ATPDraw. The generators were modeled as synchronous generators using the model SM59 for which all relevant parameters are given in table I. The transformers were modeled using the BCTRAN dialog box. For those transformers connected directly to the generators, which were assumed to be already energized at the start of the simulation, all nonlinearities were neglected. In case of the transformer to be energized, the non-linear 
behavior was modeled using the pseudo-nonlinear hysteretic inductor component Type 96 [7].

The $\Phi-I$ characteristic of the nonlinear inductor proved critical for matching the simulation results with the measurements. However, it was unfortunately not available for the investigated transformers. Therefore, it was calculated using the supporting routine HYSDAT that comes with ATP. The values for $\Phi$ and I to be inserted in HYSDAT were derived using the "View + " function of the BCTRAN dialog box. It was assumed that the positive saturation point, to be inserted in HYSDAT, lied at a voltage of 1.18 p.u., and the corresponding no-load current was assumed to equal 10 times that at a voltage of 1.1 p.u. The assumption of a factor 10 increase in the current was based on measurements taken from one of the transformers, of which no-load measurements up to a voltage of 1.18 p.u. were available. These were used to extrapolate the value for the other transformers of which only measurements up to a voltage of 1.1 p.u. were available.

\section{Power Factory Model}

In Power Factory the generators were modeled using the standard synchronous machine model. The parameters for the generators are given in table I. The transformer model in Power Factory used for the inrush simulations, is the two winding transformer model shown in figure 2 [8]. The model contains the leakage reactances at the low and high voltage side together with the winding resistance at low and high voltage side. The model also shows the magnetizing reactance $\mathrm{X}_{\mathrm{m}}$ and the ion losses resistance $\mathrm{R}_{\mathrm{Fe}}$.

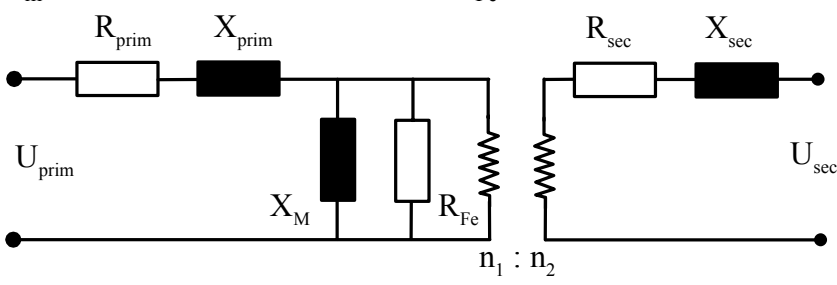

Fig. 2. Transformer model in Power Factory

To model the effect of inrush currents, the magnetizing reactance must be modeled as a function of the magnetizing current. For that, the magnetic flux is given as a function of the magnetizing current in figure 3.

The unsaturated part of the curve is determined by the simulation software from the no-load characteristics of the transformer. The saturated part and also the knee flux, the normal operating point of the transformer, is given by the $\Phi$-I characteristic of the transformer. As already mentioned, this characteristic was not known for the transformers. For the knee flux a typical value 1.04 p.u. is used. For the ratio between the gradient of the saturated and unsaturated curve, a typical value of 500 is used. This value is tuned to get a better match between simulated and measured curve of the inrush current during the simulations.

To model the remanent magnetism in Power Factory, the value of the transformer magnetizing flux is set at a predefined value (between 0 and 0.7 p.u.) at the start of a simulation.

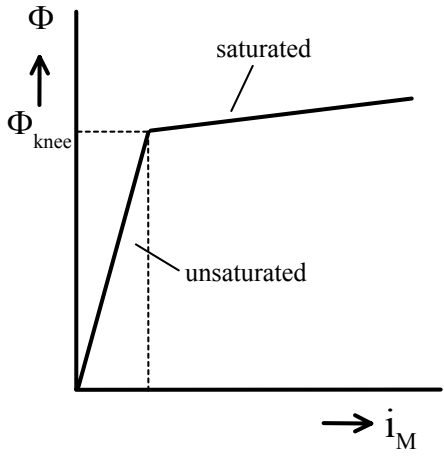

Fig. 3. Flux saturation model in Power Factory

\section{Simulation RESUlTS AND MEASUREMENTS}

\section{A. Simulation results}

Now, simulation results obtained with the models described earlier are presented. Figure 4 shows simulation results obtained with ATP and Power Factory. It shows the phase currents for the switching of the 20.0 MVA transformer (transformer 2 of system $a$ in figure 1).
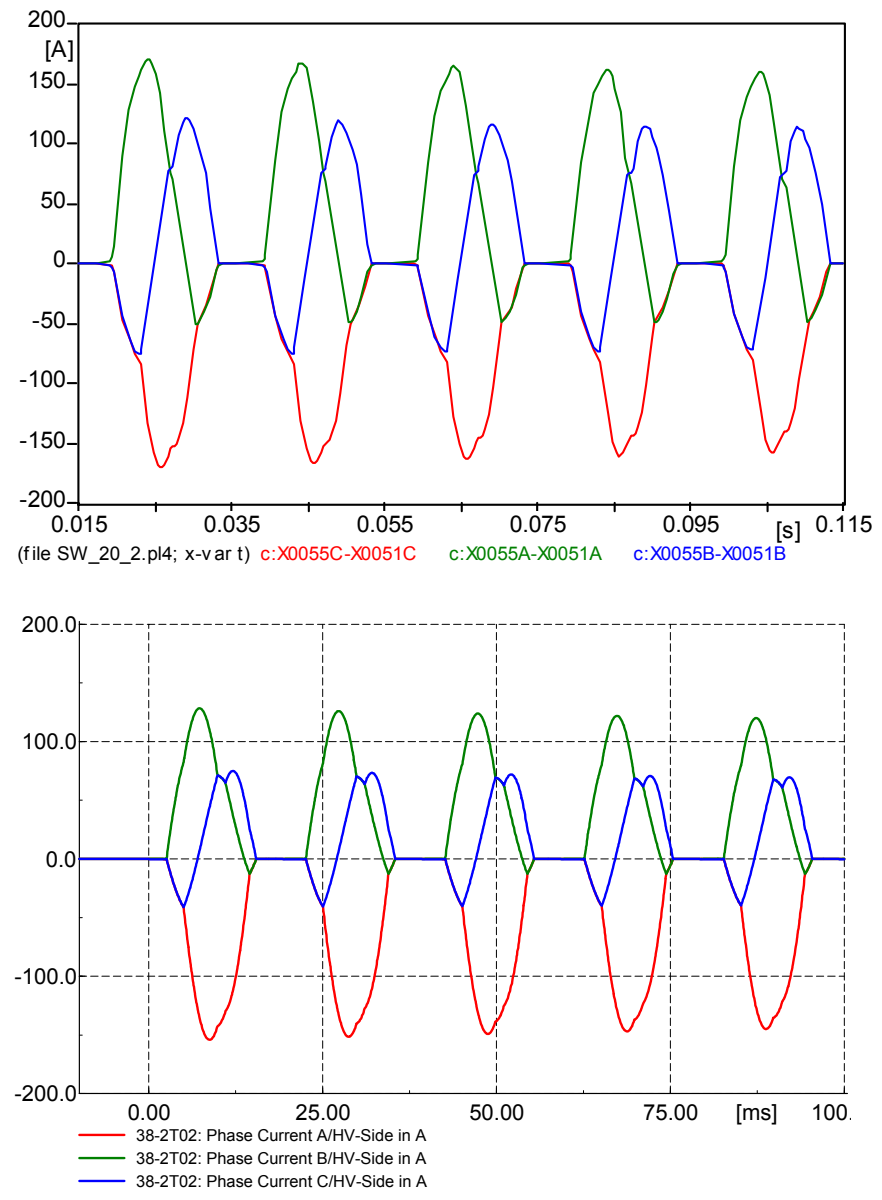

Fig. 4. Simulation of the connection of transformer 2 with ATP (above) and Power Factory (below)

In figure 5 the phase currents for the switching of the 160 MVA transformer (transformer 4 of system $b$ in figure 1) are depicted. 
The shape and amplitude of the inrush currents depend strongly on the instant of connection for both transformers. The cause of this is the physical mechanism that causes the occurrence of the inrush current, which makes them dependent on voltage at connection instant as well as on remanent magnetism, as described earlier.
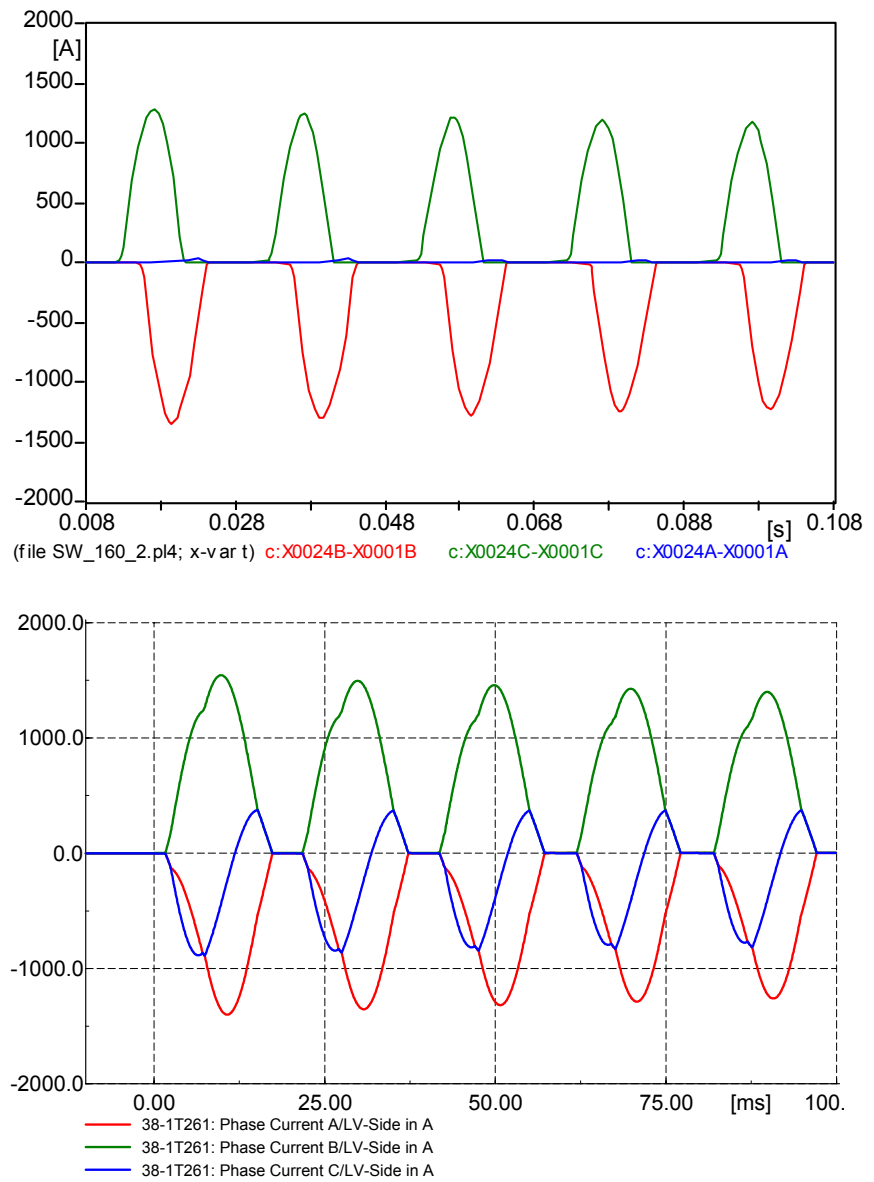

Fig. 5. Simulation of the connection of transformer 4 with ATP (above) and Power Factory (below)

Further investigations with ATP on the impact of the presence of remanent magnetism (which was created by first starting up the simulation with the transformer connected and then disconnecting and again reconnecting it) have shown that when this was included, the simulation results varied even more widely [9]. However, in the rest of this paper, remanent magnetism is not included in the ATP simulations in order to reduce the number of quantities to be varied.

The simulations with Power Factory also showed that the inrush current is dependent on the instant of connection and on the assumed amount of remanent magnetism. In the Power Factory model, the instant of connection and the amount of remanent magnetism were tuned together with the value of the slope of the saturated flux (figure 3 ) in order to get the best possible agreement between the simulation results and the measurements described in the next section.
The tuning showed that the amount of remanent magnetism and the value of the saturated flux were up to a certain extent interchangeable.

\section{B. Comparison of simulations and measurements}

In figure 6 , one of the measurements of the connection to the $66 \mathrm{kV}$ busbar is shown for transformer 2 and transformer 4. When these figures are compared to figures 4 and 5 , it can be concluded that for transformer 2 both the amplitude and shape of the measured inrush currents are quite similar to the simulation results obtained with ATP and Power Factory.
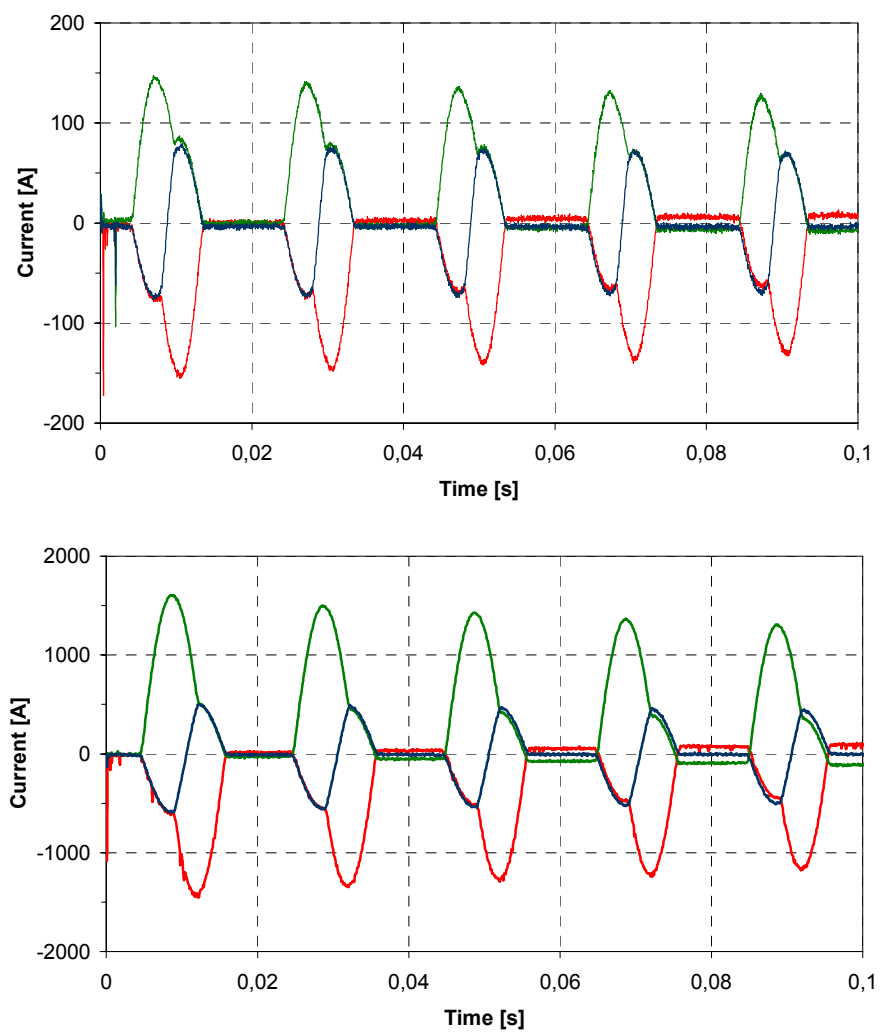

Fig. 6. Measurements of the connection of transformer 2 (above) and transformer 4 (below)

For transformer 4, the observed discrepancies both with respect to shape as well as to amplitude are larger, particularly in ATP, but to a lesser extent also in Power Factory. It proved not feasible to get a better match. Explanations for this observation could be the that the magnetizing characteristic of the iron differs more from the assumed characteristic than in case of transformer 2 or that the effect of the simplifications in the transformers model (e.g. neglecting the third winding of transformer 4, which was not present in transformer 2) negatively affect the similarity between simulation results and measurements. Further, in some cases the phases had to be exchanged to get a better correspondence. This is, however, not seen as a major weakness of the model, because in practice it does not matter very much which phase exhibits which behavior, as long as the behavior of each of the phases in the measurements is reflected in the simulation results as well. 


\section{SIMULATIONS OF RE-ENERGIZING THE GRID}

The high voltage grid in the North of the Netherlands is a $220 \mathrm{kV}$ grid. According to the test procedures for reenergizing the grid, the black-start unit has to energize the $220 \mathrm{kV}$ station it is connected to, and the first load station. The latter requires energizing of a $220 / 110 \mathrm{kV}$ transformer. Therefore the model is extended with the $2.1 \mathrm{~km}$ cable to the $220 \mathrm{kV}$ station and the 220/110 kV transformer (transformer 5). A simplified single line diagram is shown in figure 7. Before the first large size transformer is energized, the two generating units run in parallel as shown in figure 7 . The $66 / 220 \mathrm{kV}$ transformer is energized together with the $220 \mathrm{kV}$ cable.

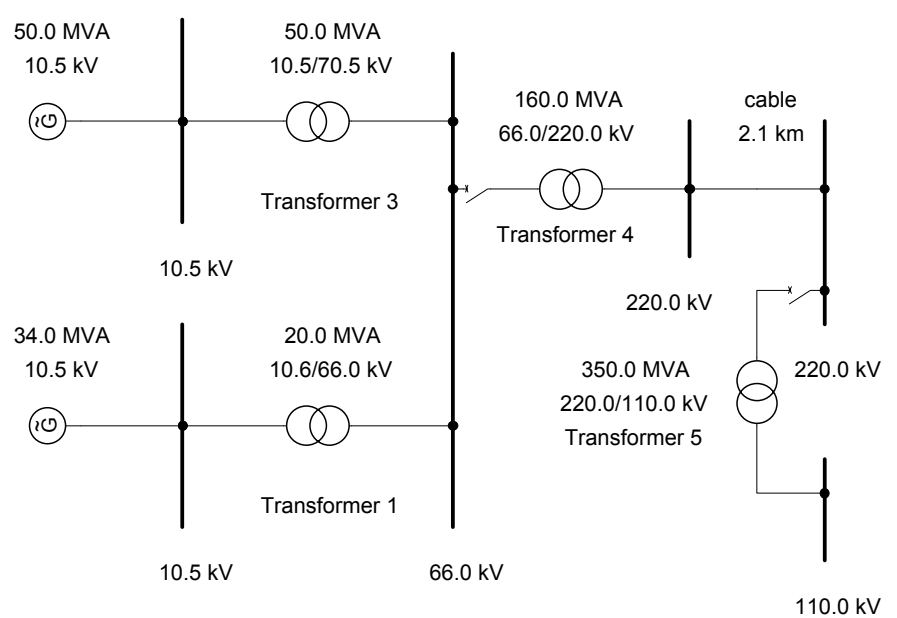

Fig. 7. Total re-energizing scheme

The simulation of this event is shown in figures 8 and 9 and gives the phase voltages at the $220 \mathrm{kV}$ terminals of the transformer.

Figure 8 shows the energizing of the transformer if the cable is not connected. Figure 9 shows the voltages with the $2.1 \mathrm{~km}$ cable connected.

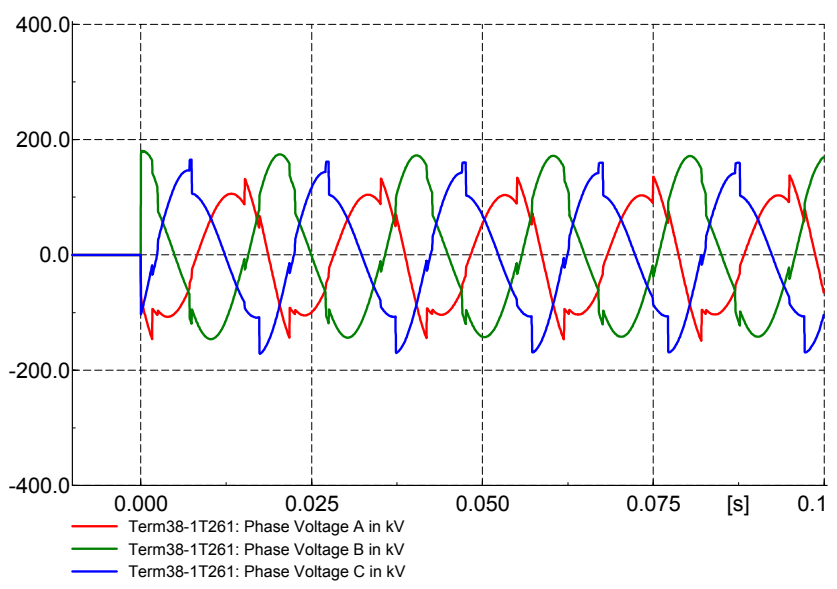

Fig. 8. Phase voltages during energizing $66 / 220 \mathrm{kV}$ transformer without cable
The maximum resonance overvoltages found in the simulations, caused by the transformer impedance and the cable capacitance, were 1.9 per unit. Similar voltages appeared at the station side of the cable.

Such voltages are not acceptable, particularly not because in the experiment the grid side of the station was in normal operation, but also not during a black-start. Therefore another black-start procedure had to be developed.

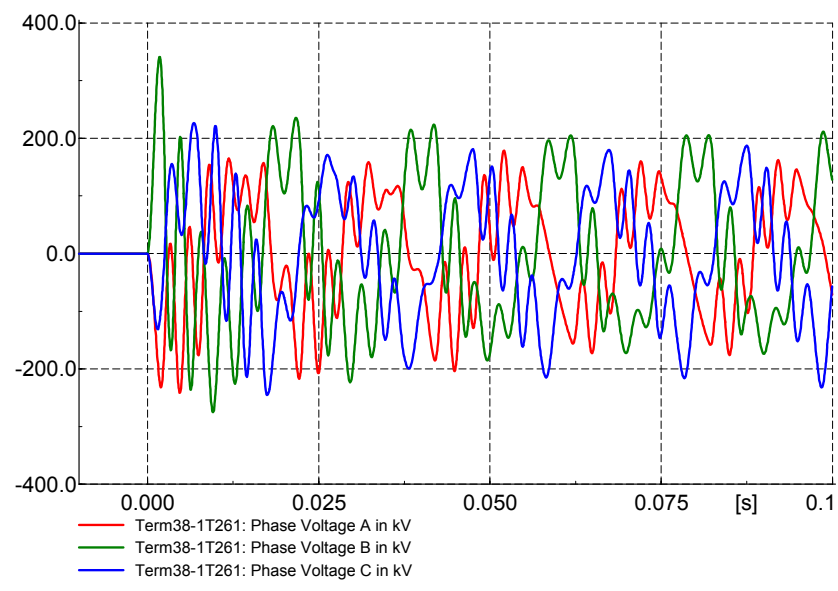

Fig. 9. Phase voltages during energizing $66 / 220 \mathrm{kV}$ transformer with cable

\section{SOFT ENERGIZING OF TRANSFORMERS}

Inrush currents of transformers and resonance overvoltages can be avoided by gradually increasing the transformer's terminal voltage to its nominal value. This is accomplished by slowly increasing the field voltage (and thus the terminal voltage) of one of the generators in the system. The ramp-up feature is often standard available on modern automatic voltage regulators (AVR).

The normal electrical schemes of a power plant are often equipped with interlocks to prevent switching operations based on potential unsafe or unwanted conditions. As an example, the logic of the circuit breaker prevents the closing of the breaker if the voltage is zero. For a soft energizing of the transformers it is therefore necessary to override these interlocks, if applicable. This means that special procedures have to be made for a soft energizing of the transformers at the power plant or the transformers in a nearby switching station.

A live test was performed to test the soft start procedure. The 50, 160 and 350 MVA transformers were connected to the $50 \mathrm{MVA}$ generator. The $34 \mathrm{MVA}$ generator and the 20 MVA transformer were disconnected. Next the 50 MVA generator is run up without excitation. The initial voltage at the terminals of the generator and thus at the terminals of the transformers are caused by remanent magnetism of the rotor of the generator. The excitation system of the $50 \mathrm{MVA}$ generator is then started with the AVR in the soft energizing mode. The ramp up time was around $10 \mathrm{~s}$. The test system was successfully energized without overvoltages occurring at the terminals of the transformers or at the busbars of the substations. The results of the test are shown in figure 10 and 
figure 11. Figure 10 shows the $66 \mathrm{kV}$ side of the transformer, figure 11 shows the $220 \mathrm{kV}$ side. At both sides of the transformer the voltage rise is smooth and reaches its end value without overvoltages.

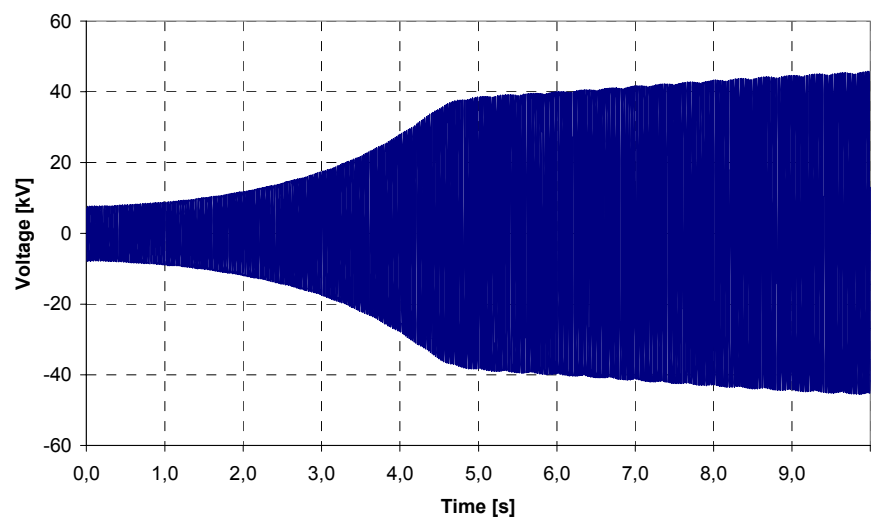

Fig. 10. Phase voltage during soft energizing at the $66 \mathrm{kV}$ side of the $66 / 220 \mathrm{kV}$ transformer

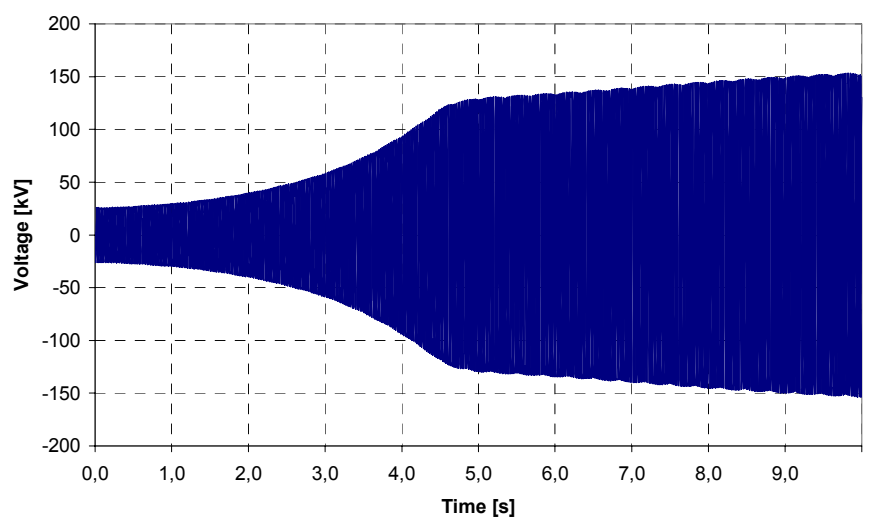

Fig. 11. Phase voltage during soft energizing at the $220 \mathrm{kV}$ side of the $66 / 220 \mathrm{kV}$ transformer

\section{CONCLUSION}

Re-energizing of the grid after a major blackout can cause problems because of the need to energize large transformers with relatively small generators. Together with the cable that connects the transformer to the grid, overvoltages can occur at the terminals of the transformer and at the busbars of substations. Such problems can be avoided by soft energizing the transformers. This requires the black-start unit to be equipped with possibilities to make the appropriate connections (interlock overrides) and a soft energizing mode on its automatic voltage regulator.

Simulations were performed to test energizing procedures of a particular power plant prior to live testing. First, the physical origin of inrush currents was described. Then, it was discussed how inrush currents can be simulated using two state of the art power systems simulation software packages. Particular attention was paid to the modeling of the transformer including magnetic saturation. It was indicated that in most cases not all necessary data is available, so that either measurements must be available to tune the model or assumptions must be made. In the latter case, the modeling approach presented in the paper could be used advantageously for formulating these assumptions.

Simulation results obtained with the developed models were presented and it was shown that the shape and the amplitude of the inrush currents strongly depend on the connection instant, as well as on the assumptions with respect to the amount of remanent magnetism. The simulation results were compared with measurements. It was concluded that the degree of correspondence was satisfactory, although differences remain, which vary from case to case. Factors explaining these could be discrepancies between the shape of the modeled and the real magnetizing characteristic and the impact of remanent magnetism. The developed models were used to simulate the re-energizing of the grid.

Based on the simulation results, the procedure was modified to use soft energizing instead of direct switching. Live tests were performed using the new procedure, resulting in the confirmation of the unit's black-start capability.

\section{ACKNOWLEDGMENT}

Delesto B.V. is acknowledged for carrying out the measurements, providing the equipment data and supporting the work reported in the paper. Assistance of TenneT bv and Essent Netwerk B.V. was available for the switching operations in the $220 \mathrm{kV}$ and $110 \mathrm{kV}$ Public Grid of the Netherlands.

\section{REFERENCES}

[1] C. Saldana, G. Calzolari, 'Methodology Utilized in Black-start Studies on EHV Power Networks," presented at the IV International Conference on Power System Transients, IPST'2001, Rio de Janeiro, Brazil, 2001

[2] C.P. Cheng, Shihe Chen, "Simulation of Resonance Over-voltages during Energizing of High Voltage Power Network," presented at the V International Conference on Power System Transients, IPST'2003, New Orleans, Louisiana, 2003

[3] M.M. Adibi, R.W. Alexander, B. Avramovic, 'Overvoltage Control During Restoration," IEEE Transactions on Power Systems, Vol 7, No4, Nov 1992

[4] M.J. Heathcote, 1998, The J\&P Transformer Book, Reed Educational and Professional Publishing, Oxford.

[5] J.J. Winders, 2004, Power Transformers, Marcel Dekker, New York.

[6] http://www.allaboutcircuits.com/vol_2/chpt_9/12.html

[7] Can/Am EMTP User Group, 1995, Rule Book-Alternative Transient Program, Oregon.

[8] DIgSILENT, 2004, Power Factory Version 13; User Manual, Gomaringen.

[9] M. Rioual, C. Sicre, ''Energization of a no-load transformer for power restoration purposes: Impact of the sensitivity to parameters," presented at the IV International Conference on Power System Transients, IPST'2001, Rio de Janeiro, Brazil, 2001

\section{BIOGRAPHIES}

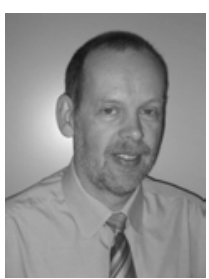

Kees P.J. Jansen received the MSc degree in Electrical Engineering from the University of Technology Eindhoven (TUE), The Netherlands, in 1982. From 1983 to 1986 he was with ASEA in Sweden. Since 1986 he works at KEMA in Arnhem, The Netherlands. He holds a senior consulting position with KEMA. He is involved in system studies and network design and calculations for public networks and industrial installations. 


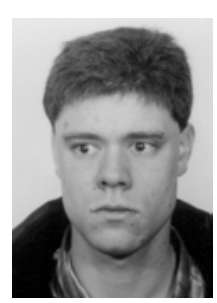

Han G. Slootweg received a MSc degree in electrical engineering in 1998 (cum laude) and a $\mathrm{PhD}$ degree in 2003, both from Delft University of Technology, the Netherlands. He also holds a MSc degree in business administration. Currently, Han works with Essent Netwerk B.V., one of the largest Distribution Network Operators of The Netherlands, where he is responsible for the coordination of the maintenance and the long term planning of the company's $110 \mathrm{kV}$ and $150 \mathrm{kV}$ networks.

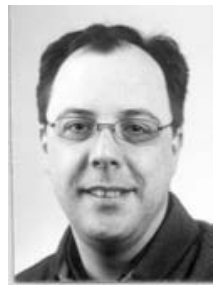

Richard A.C.T. de Groot MIEE received the MSc degree in Electrical Engineering from Delft University of Technology, The Netherlands, in 1992. Until 2000 he was with Holec Projects (now Strukton Systems) as electrical project/design engineer for power plants and substations. He is currently with KEMA in Arnhem, The Netherlands, as senior consultant in Power System Design and Analysis. He is involved in system studies, network design and connection studies. 